$\begin{array}{ll}\text { UNNES } & \text { J.of Biol.Educ.7 (2) (2018) } \\ \text { Unttp://journal.unnes.ac.id/sju/index.php/ujbe }\end{array}$

\title{
Keefektifan Model Pembelajaran Window Shopping dan Pendekatan Jelajah Alam Sekitar pada Materi Ekosistem
}

\author{
Nur Zumroh ${ }^{1 凶}$, Enni Suwarsi Rahayu ${ }^{1}$, Nur Kusuma Dewi ${ }^{2}$ \\ Jurusan Biologi, FMIPA, Universitas Negeri Semarang, Indonesia
}

\begin{tabular}{|c|c|}
\hline Info Artikel & Abstrak \\
\hline $\begin{array}{l}\text { Sejarah Artikel: } \\
\text { Diterima: April } 2018 \\
\text { Disetujui: Juli } 2018 \\
\text { Dipublikasikan: } \\
\text { Agustus } 2018\end{array}$ & $\begin{array}{l}\text { Kegiatan laboratorium dan pemanfaatan lingkungan sekitar Madrasah Aliyah (MA) } \\
\text { Salafiyah Pati Jawa Tengah belum dilakukan sepenuhnya dalam pembelajaran biologi. Akibatnya, } \\
\text { hasil belajar siswa kurang optimal. Masalah tersebut diprediksi model pembelajaran Window Shopping } \\
\text { (WS) dan pendekatan Jelajah Alam Sekitar (JAS). Tujuan penelitian ini untuk menganalisis keefektifan } \\
\text { WS dan JAS pada materi ekosistem. Jenis penelitian ini adalah Quasy Experimental menggunakan } \\
\text { Pretest-Posttest Design. Populasi penelitian adalah sembilan kelas X. Sampel penelitian adalah kelas XE }\end{array}$ \\
\hline $\begin{array}{l}\text { Kata kunci: } \\
\text { effectiveness, appropriate } \\
\text { nature approach; } \\
\text { window shopping; } \\
\text { ecosystem material }\end{array}$ & $\begin{array}{l}\text { (kontrol), XF (WS disertai JAS), dan XG (JAS). Sampel diambil menggunakan teknik purposive } \\
\text { sampling. Variabel penelitian berupa hasil belajar kognitif, afektif, dan psikomotorik. Data dianalisis } \\
\text { menggunakan N gain, ketuntasan klasikal, ANAVA, BNT, dan deskriptif persentase. Hasil penelitian } \\
\text { menunjukkan bahwa kelas dengan WS dan JAS menunjukkan N gain kategori tinggi, nilai rata-rata } \\
\text { kelas paling tinggi dan persentase ketuntasan klasikal paling tinggi pula. Semua kelas memperoleh nilai } \\
\text { afektif dan psikomotorik dengan kriteria sangat baik. Berdasarkan hasil tersebut dapat disimpulkan } \\
\text { bahwa penggunaan model pembelajaran WS dan JAS pada materi ekosistem di MA Salafiyah Pati } \\
\text { Jawa Tengah efektif meningkatkan hasil belajar siswa. }\end{array}$ \\
\hline
\end{tabular}

\section{Abstract} Laboratory activities and environment utilization around Madrasah Aliyah (MA) Salafiyah Pati
Central Java has not been done completely in biology learning. As a result, student learning outcomes are less than
optimal. The problem is predicted by Window Shopping (WS) learning model and the surrounding nature roaming
approach (JAS) as an alternative learning. The purpose of this research is to analyze the effectiveness of WS
learning model and JAS approach on ecosystem material in MA Salafiyah Pati Central of Java. This type of
research is Quasy Experimental using Pretest-Postetst Design. The population was nine class of X. The sampling
was XE class (control), XF (WS accompanied by JAS), and XG (JAS). Samples were taken using purposive
sampling technique. The research variables are cognitive learning outcomes, affectiveand psychomotor. Class of WS
and JAS of N-gain is high category, the highest grade average grade and percentage of classical completeness
higest. All classes get affective and psychomotor value with very good criteria. Based on these result can be concluded
that use of learning models WS and JAS on ecosystem materials in MA Salafiyah Pati Central of Java effectively
improve student learning outcomes. 


\section{PENDAHULUAN}

Dinamika pendidikan saat ini telah berubah dari pembelajaran yang berpusat pada guru (teacher centered learning) menjadi pembelajaran yang berpusat pada siswa (student centered learning). Dengan berubahnya dinamika pendidikan ini, maka guru dituntut agar selalu mengadakan inovasiinovasi dalam melaksanakan pembelajaran secara terus menerus berkesinambungan, guru juga harus merancang sebuah model pembelajaran yang menuntut siswa lebih aktif (Depdikbud, 2014) Beberapa Madrasah Aliyah (MA) juga perlu membekali siswanya dengan berbagai macam kecakapan hidup mengingat perkembangan zaman semakin pesat. Hasil wawancara dengan salah satu guru biologi di MA Salafiyah Pati Jawa Tengah pada bulan Januari 2017 menunjukkan bahwa kegiatan laboratorium dan pemanfaatan lingkungan alam sekitar dalam pembelajaran biologi materi ekosistem di kelas X MA jarang dilakukan, green school yang terdapat di MA Salafiyah Pati Jawa Tengah juga kurang dimanfaatkan, partisipasi aktif siswa dalam pembelajaran dan hasil belajar kurang maksimal.

Salah satu upaya yang dapat dilakukan guru untuk menciptakan agar hasil belajar maksimal adalah melalui model pembelajaran WS dan pendekatan JAS. Menurut Susilowati et al., (2008), pendekatan JAS memiliki beberapa keunggulan yaitu pertama, memberikan keleluasaan bagi siswa untuk membangun gagasan yang muncul dan berkembang setelah pembelajaran berakhir. Kedua, tanggung jawab belajar berada pada siswa dan guru mempunyai tanggung jawab menciptakan situasi yang mendorong motivasi belajar siswa. Ketiga, JAS menekankan pada pembelajaran yang menyenangkan, melibatkan ilmu sains, proses penemuan ilmu, ketrampilan berkarya, kerjasama, permainan yang mendidik, kompetisi, tantangan, dan sportivitas.

Ngabekti (2017) mengemukakan bahwa keenam komponen JAS membelajarkan biologi sesuai dengan hakikat biologi, menjadikan belajar lebih bermakna dan memberikan pengalaman belajar yang lebih bermanfaat karena pembelajaran menjadi kontekstual. Selain itu, melalui pembelajaran biologi dengan pendekatan JAS disertai model pembelajaran WS diharapkan siswa memiliki ketrampilan menciptakan sebuah karya atau produk yang kemudian dipresentasikan atau dipamerkan dari kelompok satu ke kelompok lain. Dalam pembelajaran menggunakan model ini tidak hanya terdapat kerja kelompok, namun juga terdapat kegiatan saling berbagi ilmu ke kelompok lain. Pembelajaran model JAS disertai WS mencakup kegiatan kerja kelompok dan tutor sebaya. Model pembelajaran ini dapat digunakan untuk mengetahui tingkat pemahaman siswa dan juga memberi latihan yang bersifat pemecahan masalah (Rismawati, 2014).

Rumusan masalah dalam penelitian ini adalah bagaimana keefektifan model pembelajaran WS dan pendekatan JAS pada materi ekosistem di Madrasah Aliyah Salafiyah Pati Jawa Tengah. Penelitian ini bertujuan untuk mengetahui keefektifan model pembelajaran WS dan pendekatan JAS pada materi ekosistem di MA Salafiyah Pati Jawa Tengah.

\section{METODE PENELITIAN}

Penelitian dilaksanakan pada bulan Mei-Juni 2017, yaitu pada semester genap tahun ajaran 2016/2017 di MA Salafiyah Pati Jawa Tengah. Penelitian ini menggunakan metode Quasy Experiment dengan rancangan penelitian Pretest-Posttest Design (Sugiyono, 2014; 2015). Populasi penelitian adalah sembilan kelas X MA Salafiyah Pati Jawa Tengah. Sampel penelitian sebanyak tiga kelas yaitu kelas XE (sebagai kontrol), XF (pembelajaran menggunakan WS yang disertai JAS), dan XG (pembelajaran dengan JAS saja). Sampel diambil menggunakan teknik purposive sampling. Variabel bebas dalam penelitian ini adalah penerapan model pembelajaran WS dan pendekatan JAS. Variabel kontrolnya adalah materi ekosistem di MA Salafiyah Pati Jawa Tengah, jumlah jam pelajaran, soal evaluasi, waktu belajar, dan guru biologi. Sedangkan variabel terikatnya adalah hasil belajar kognitif, afektif, dan psikomotorik. Hasil belajar siswa yang diukur adalah hasil belajar 
kognitif siswa sebagai hasil belajar utama dan hasil belajar pendukung meliputi hasil belajar afektif dan psikomotorik.

Hasil belajar kognitif diukur dengan pretest dan posttest, sedangkan ranah afektif dan psikomotorik diukur dengan observasi. Data hasil belajar kognitif dianalisis dengan uji N-gain, ketuntasan klasikal, uji anava, dan uji lanjut BNT (Beda Nyata Terkecil). Data hasil belajar afektif dan psikomotorik dianalisis menggunakan deskriptif persentase. Hasil belajar siswa dikatakan efektif apabila $\geq 80 \%$ mencapai kriteria ketuntasan minimal (KKM) sebesar 75, Perbedaan hasil belajar yang signifikan dibuktikan dengan uji anava skor posttest dengan $\mathrm{F}_{\text {hitung }}>\mathrm{F}_{\text {tabel }}$ dan signifikansi uji lanjut BNT (Beda Nyata Terkecil), Peningkatan hasil belajar (N-Gain) siswa kelas eksperimen $\geq 70 \%$ berada pada kategori sedang sampai dengan tinggi. Hasil belajar siswa juga dilihat dari aspek afektif dan psikomotorik melalui observasi pada saat pembelajaran berlangsung ketika diskusi kelompok, yaitu saat kegiatan eksplorasi dan WS rata-rata termasuk kategori sangat baik atau baik.

\section{HASIL DAN PEMBAHASAN}

Hasil penelitian menunjukkan bahwa ketuntasan klasikal kelas WS dan JAS paling tinggi dibanding kelas lain. Hasil uji ANAVA signifikan. Hasil uji BNT kelas WS dan JAS paling tinggi secara signifikan dibanding kelas lain (Tabel 1).

Tabel 1 Uji lanjut BNT ( $\alpha=1 \%)$

\begin{tabular}{lll}
\hline Kelas & Rata-rata nilai & Keterangan \\
\hline Kontrol & $80,30^{\mathrm{c}}$ & Berbeda signifikan \\
Eksperimen 1 & $90,80^{\mathrm{a}}$ & Berbeda signifikan \\
Eksperimen 2 & $85,45^{\mathrm{b}}$ & Berbeda signifikan \\
\hline
\end{tabular}

Tabel 2 Hasil N-gain

\begin{tabular}{llllll}
\hline Kelas & Rata-rata & Kategori & \multicolumn{2}{l}{ Jumlah Siswa yang mendapatkan N gain (\%) } \\
& N gain & & & Sedang & Rendah \\
\cline { 4 - 6 } & & & Tinggi & $18,18 \%$ & $0 \%$ \\
\hline Kontrol & 0,81 & Tinggi & $81,82 \%$ & $54,84 \%$ & $3,22 \%$ \\
Eksperimen 1 & 0,69 & Sedang & $41,94 \%$ & $69,70 \%$ & $9,09 \%$ \\
Eksperimen 2 & 0,57 & Sedang & $21,1 \%$ & & \\
\hline
\end{tabular}

Indikator keefektifan pembelajaran tidak hanya dilihat dari ketuntasan klasikal dan rata-rata nilai saja, melainkan juga $\mathrm{N}$ gain untuk mengetahui besarnya peningkatan hasil belajar siswa sebelum dan sesudah diberi perlakuan. Rata-rata N-gain kelas WS dan JAS termasuk kategori tinggi, sedangkan kelas JAS saja dan kelas kontrol termasuk kategori sedang (Tabel 2). Berdasarkan analisis hasil belajar kognitif kelas kelas WS dan JAS, kelas JAS saja, dan kelas kontrol dapat diketahui bahwa pembelajaran dengan menggunakan pendekatan WS disertai JAS pada materi ekosistem di MA Salafiyah Pati Jawa Tengah terjadi peningkatan hasil belajar siswa yang lebih tinggi dibandingkan pembelajaran dengan pendekatan JAS saja, serta pembelajaran dengan ceramah.

Hasil belajar kognitif masih terdapat siswa yang tidak tuntas KKM, khususnya kelas WS dan JAS, dan kelas JAS saja. Hal ini diduga dipengaruhi oleh beberapa faktor antara lain faktor internal dan eksternal. Faktor internal tersebut berupa motivasi siswa yang timbul karena ketertarikan pada saat kegiatan JAS dan WS yang menarik dan melibatkan siswa, serta belajar 
dengan lingkungan sekitar secara langsung, sehingga siswa tidak merasa bosan saat proses pembelajaran berlangsung, serta faktor eksternal yang meliputi faktor keluarga, faktor sekolah dan faktor lingkungan. Faktor lainnya meliputi kondisi sosial dan alam. Pada penelitian kondisi sosial dari lingkungan sekolah antara lain kerjasama teman sebaya dalam proses pembelajaran berlangsung dan interaksi siswa dengan teman sebaya, gurunya, serta alam sekitar (Dimyati \& Mudjiono, 2009.

Siswa yang tidak tuntas tersebut pada saat pembelajaran terlihat aktif, tetapi belum sepenuhnya memahami materi yang disampaikan oleh guru karena masing-masing siswa memiliki tingkat pemahaman yang berbeda-beda sehingga hasil belajarnya kurang memuaskan. Hal tersebut sesuai dengan teori Slameto (2010) bahwa berhasil tidaknya seseorang dalam belajar disebabkan oleh faktor internal dan faktor eksternal. Faktor internal adalah faktor dari dalam diri siswa meliputi kesehatan, intelegensi, bakat, minat, dan motivasi serta cara belajar (Sardiman, 2007; Sudjana, 2010; Sugihartono, 2007). Faktor eksternal yang mempengaruhi dalam belajar meliputi faktor keluarga dan faktor sekolah. Berdasarkan beberapa faktor tersebut, perlu adannya upaya perbaikan misalnya dengan diadakannya remidial, penugasan khusus, ataupun menambah jam belajar siswa melalui kegiatan pengayaan bagi siswa yang bersangkutan agar dapat mencapai ketuntasan belajar.

Keberhasilan pembelajaran menggunakan model pembelajaran WS dan pendekatan JAS materi ekosistem di MA juga diperkuat dengan data pendukung dari nilai afektif dan psikomotorik. Siswa kelas WS dan JAS, kelas JAS saja, dan kelas kontrol mendapatkan nilai afektif dan psikomotorik dengan kriteria sangat baik. Namun, jumlah siswa yang memperoleh kriteria sangat baik pada kelas WS dan JAS lebih tinggi dibandingkan kelas lain. Hal ini membuktikan bahwa model pembelajaran WS dan pendekatan JAS dapat mempengaruhi perubahan sikap sosial seperti disiplin, tanggung jawab, menghargai pendapat orang lain, mendorong siswa untuk bersikap peduli lingkungan, dan melatih kerjasama. Hal ini juga diperkuat dengan nilai psikomotorik pada kelas WS dan JAS yang memiliki keterampilan menciptakan sebuah karya atau produk, yaitu berupa maket, poster, atau sejenisnya yang kemudian dipresentasikan atau dipamerkan dari kelompok satu ke kelompok lain.

Penggunaan WS dan JAS sesuai dengan teori Rahma (2017) bahwa model pembelajaran WS, siswa tidak hanya melihat hasil pekerjaan kelompok lain tetapi juga mencatat hasil pekerjaan tersebut untuk saling berbagi dengan anggota kelompoknya. Sehingga setiap anggota yang berkunjung juga berbelanja ilmu untuk oleh-oleh anggota lainnya khususnya anggota yang bertugas sebagai "penjaga toko". Selain itu, Susilowati et al., (2008) mengemukakan bahwa pendekatan JAS memiliki beberapa keunggulan yaitu pertama, memberikan keleluasaan bagi siswa untuk membangun gagasan yang muncul dan berkembang setelah pembelajaran berakhir. Kedua, tanggung jawab belajar berada pada siswa, dan guru mempunyai tanggung jawab menciptakan situasi yang mendorong motivasi belajar siswa (Winarni, 2013). Ketiga, JAS menekankan pada pembelajaran yang menyenangkan, melibatkan ilmu, sains, proses penemuan ilmu, ketrampilan berkarya, kerjasama, permainan yang mendidik, kompetisi, tantangan, dan sportivitas (Marianti \& Kartijono, 2005; Samitra et.al., 2016).

Hal tersebut didukung oleh penelitian yang dilakukan Ngabekti (2006) menunjukkan bahwa pendekatan JAS dipadukan dengan metode bermain peran pada materi ekosistem di Pondok Pesantren Modern Selamet Kendal dapat meningkatkan aktivitas dari hasil belajar peserta didik dan penelitian yang dilakukan Aulannisa (2015) menunjukkan bahwa pendekatan JAS berpengaruh terhadap hasil belajar siswa. Penggunaan model pembelajaran WS dan pendekatan JAS juga dapat diterapkan pada materi lain seperti keanekaragaman hayati, ruang lingkup biologi, dan lain sebagainya yang memerlukan lingkup belajar WS dan JAS. 


\section{SIMPULAN}

Berdasarkan hasil penelitian dan pembahasan dapat disimpulkan bahwa pembelajaran dengan menggunakan model pembelajaran WS dan pendekatan JAS efektif dalam pembelajaran materi ekosistem di MA Salafiyah Pati Jawa Tengah. Keefektifan ditunjukkan dengan hasil belajar siswa pada ranah kognitif, afektif, dan psikomotorik penilaian sudah memenuhi kriteria.

Hasil belajar kognitif kelas WS dan JAS mencapai ketuntasan klasikal, N gain termasuk kategori tinggi, dan lebih tinggi secara signifikan dibandingkan kelas lain. Hasil belajar afektif dan psikomotorik termasuk kriteria sangat baik. Penggunaan model pembelajaran WS dan pendekatan JAS juga dapat diterapkan pada materi lain seperti keanekaragaman hayati, ruang lingkup biologi, dan lain sebagainya yang memerlukan lingkup belajar WS dan JAS.

\section{DAFTAR PUSTAKA}

Aulannisa, I. 2015. Penerapan Pendekatan Jelajah Alam Sekitar Pada Pembelajaran Materi Ekosistem Kelas X di SMA Negeri 1 Prembun. Skripsi. Universitas Negeri Semarang

Dimyati \& Mudjiono. 2009. Belajar dan Pembelajaran. Jakarta: PT Rineka Cipta.

Depdikbud. 2014. Peraturan Menteri Pendidikan Dan Kebudayaan Republik Indonesia Nomor 104 dan 103 Pasal 2 ayat 1, 7, dan 8 Tahun 2014 tentang Pembelajaran Pada Pendidikan Dasar Dan Menengah. Jakarta: Departemen Pendidikan dan Kebudayaan.

Marianti, A. \& Kartijono, N.E. 2005. Jelajah Alam Sekitar (JAS). Dipresentasikan pada Seminar dan

Lokakarya Pengembangan Kurikulum dan Desain Inovasi Pembelajaran jurusan biologi FMIPA Unnes dalam rangka pelaksanaan PHK A2. Semarang: Biologi FMIPA Unnes.

Ngabekti, S. 2017. Pendekatan Jelajah Alam Sekitar Implementasi dalam Pembelajaran. Semarang : FMIPA Unnes

Rahma, Wahyuni. 2017. Pengaruh Penggunaan Metode Kooperatif Window Shopping terhadap Partisipasi

Bimbingan Konseling Klasikal. Jurnal Penelitian Pendidikan Indonesia, Volume : 2, Nomor : 2,

April, halaman 2.

Rismawati. 2013. Peningkatan Kemampuan Menulis Puisi Melalui Penggunaan Model Berbelanja (Windows Shopping) : Jurnal Ilmiah Mahasiswa Pendidikan Bahasa dan Sastra Indonesia Fakultas Keguruan dan Ilmu Pendidikan Universitas Galuh.

Samitra, D., Widiya, M., Rahmasari, ND. 2016. Pengaruh Pendekatan Jelajah Alam Sekitar (JAS) Terhadap Keterampilan Proses dan Hasil Belajar Biologi Siswa Kelas X SMA Negeri 5 Lubuklinggau.

Sardiman. 2007. Interaksi dan Motivasi Belajar Mengajar. Jakarta: Raja Grafindo Persada.

Slameto. 2010. Belajar dan Faktor-Faktor yang Mempengaruhinya. Jakarta: Rineka Cipta.

Sudjana. 2010. Dasar-Dasar Proses Belajar Mengajar. Bandung: Sinar Baru Algensindo.

Sugihartono.2007. Psikologi Pendidikan. Yogyakarta: UNY Press.

Sugiyono. 2014. Metode Penelitian Kuantitatif, Kualitatif dan R\&D. Bandung: Alfabeta Rosdakarya. 2015. Metode Penelitian Kuantitatif, Kualitatif dan R\&D. Bandung: Alfabeta Rosdakarya.

Susilowati, SME., Sari, YK., Ridlo, S. 2008. Efektivitas Penerapan Metode Quantum Teaching pada Pendekatan Jelajah Alam Sekitar (JAS) Berbasis Karakter dan Konservasi: Unnes Journal of Biology Education.

Winarni, EW. 2013. Perbandingan Sikap Peduli Lingkungan, Keterampilan Proses dan Pemahaman Konsep antara Siswa Pada Pembelajaran IPA Menggunakan Pendekatan Jelajah Alam Sekitar (JAS) dan Ekspositori di Sekolah Dasar. Jurnal Ilmiah PGSD, Volume: 5, Nomor:1, April, halaman 145. 